\title{
Avaliação do uso do resíduo farelo de babaçu (Orbignya sp) na alimentação de ruminantes*
}

\author{
Evaluation of use of waste meal babassu (Orbignya sp) in ruminant diets \\ Évaluation de l'utilisation de farine des déchets babassu (Orbignya sp) dans \\ l'alimentation des ruminants
}

Evaluación del uso de residuo la harina de babasú (Orbignya sp) en la dieta de los rumiantes

\author{
Maria Alzira Garcia de Freitas** \\ garciafreitasmariaalzira@yahoo.com.br \\ Guilherme Benko Siqueira** \\ guibenko@uft.edu.br \\ Flávia Lucila Tonani Siqueira** \\ flaviatonani@uft.edu.br
}

Recebido em 28/01/2013; revisado e aprovado em 23/03/2013; aceito em 17/06/2013

\begin{abstract}
Resumo: A procura por alternativas alimentares regionais que contribuam com a redução do custo na produção de ruminantes motivou avaliar o valor nutricional do farelo de babaçu em níveis crescentes na dieta. $\mathrm{O}$ delineamento experimental foi em blocos casualizados, com quatro tratamentos e seis repetições. Concluiu-se que esse farelo apresenta um valor nutricional relativamente baixo para a alimentação de ruminantes. Sua utilização não deve exceder a $20 \%$ da IMS.

Palavras-chave: Digestibilidade. Ovinos. Valor Energético.

Abstract: The demand for regional food alternatives that contribute to cost reduction in ruminant production motivated evaluate the nutritional value of babassu meal at increasing levels in the diet. The experimental design was a randomized block with four treatments and six repetitions. It was concluded that this meal has a relatively low nutritional value to ruminant feed. Its use should not exceed $20 \%$ of the IMS.

Key words: Digestibility. Sheep. Energy Value.

Résumé: La demande pour des alternatives alimentaires régionales qui contribuent à la réduction des coûts de production des ruminants motivé évaluer la valeur nutritionnelle des farine de babassu à des niveaux croissants dans l'alimentation. Le dispositif expérimental était un bloc randomisé avec quatre les traitements et les six des répétitions. Il a été conclu que ce farine a une valeur relativement faible nutritionnel pour l'alimentation des ruminants. Son utilisation ne doit pas dépasser 20\% de l'IMS.

Mots-clés: Digestibilité. Moutons. Valeur énergétique.

Resumen: La demanda de alternativas regionales de alimentos que contribuyen a la reducción de costos en la producción de rumiantes motivó evaluar el valor nutritivo de la harina de babasú en niveles cada vez mayores en la dieta. El diseño experimental fue en bloques al azar con cuatro tratamientos y seis repeticiones. Se concluyó que esta comida tiene un valor nutricional relativamente bajo de alimentación de los rumiantes. Su uso no debe exceder el $20 \%$ de la IMS.

Palabras clave: Digestibilidad. Ovejas. Valor Energético.
\end{abstract}

\section{Introdução}

A preocupação com as questões ambientais e produção de alimentos para o consumo interno, com a qualidade dos produtos e com o consumo de energia vem incentivando vários setores industriais a buscar tecnologias mais limpas e eficientes.

Diante da necessidade de diversificação de fontes energéticas, o Brasil se sobressai devido à grande extensão territorial e à diversidade de solo e clima do país que são propícios para a agricultura de energia (GOLDEMBERG; MOREIRA, 2005).

No Brasil, a formulação de rações tem como alimentos tradicionalmente utilizados: o milho e o farelo de soja. Esses dois alimentos chegam a representar $90 \%$ do total de ingredientes das rações, constituindo grande parte dos custos relativos à alimentação e,

\footnotetext{
* Dissertação apresentada por Maria Alzira Garcia de Freitas à Universidade Federal do Tocantins (UFT) como parte dos requisitos para obtenção do Título de Mestre em Agroenergia (Área de concentração em Processos de obtenção de biocombustíveis e avaliação de aproveitamento de seus resíduos).

** Universidade Federal do Tocantins, Palmas, TO, Brasil.
} 
consequentemente, dos custos totais de produção. Tais alimentos estão sujeitos a intensas oscilações de preço (PASCOAL et al., 2006). Surge como um desafio para os nutricionistas, prosseguem os autores, a busca constante de alimentos alternativos que possam substituir os alimentos tradicionalmente utilizados no país, de forma a reduzir custos e manter, ou até mesmo melhorar o desempenho dos animais. É necessário, portanto, um conhecimento das características desses alimentos, bem como suas possíveis limitações devido a aspectos químicos, físicos e econômicos.

Mediante o exposto, a elaboração deste projeto foi fruto da pergunta: Seria o farelo residual do coco babaçu fonte alternativa na alimentação de ruminantes?

Dessa forma, este trabalho teve como objetivo avaliar o uso do farelo do coco babaçu, coproduto da produção do óleo, como alimento alternativo para suplementação de ruminantes. Por isso o estudo da viabilidade nutricional do farelo de babaçu nesta pesquisa representa um importante avanço no conhecimento das possibilidades de aplicação desse coproduto na alimentação de ruminantes.

\section{Material e métodos}

O experimento constou de um ensaio de digestibilidade conduzido nas instalações do setor de Ovinocultura AGNUS ${ }^{\circledR}$ - Aprisco na Fazenda Ouvidor, localizada no município de Monte Santo de Minas, MG. A fazenda está situada a $21^{\circ} 08^{\prime} 52.50^{\prime \prime}$ latitude sul, 46 $56^{\prime} 58.86^{\prime \prime}$ longitude oeste e a $911 \mathrm{~m}$ de altitude.

O experimento foi realizado no período de 15/07/2011 a 13/08/2011 e contou com dois períodos de coletas de cinco dias cada um e dois períodos de adaptação dos animais às dietas, às gaiolas e ao manejo experimental de dez dias, que antecederam cada fase de coleta. Os animais foram instalados em gaiolas metálicas individuais adequadas para ensaios de digestibilidade in vivo, providas de comedouro e bebedouro. Cada gaiola metabólica possuía, acoplado ao assoalho, um sistema de captação de fezes e urina. As fezes foram recolhidas em bandejas de plástico branco, medindo $365 \times 235 \times 70 \mathrm{~mm}$; e a urina foi recolhida em potes de vidro transparente de $1.300 \mathrm{~mL}$ adaptados com uma tela separadora, evitando que as fezes e a urina ficassem em contato. Em cada pote foram colocados 100 $\mathrm{mL}$ de ácido clorídrico $(\mathrm{HCl})$ a $5 \%$ para acidificar a urina, evitando perdas nitrogenadas por volatilização.

Foram utilizados doze (12) cordeiros machos em crescimentos da raça Santa Inês, com peso vivo médio $26,82 \mathrm{~kg}$. Os animais foram vermifugados uma única vez durante todo o ensaio experimental com endoparasiticida injetável (Ivermectina 3,15\%).

A alimentação dos animais consistiu de feno de capim Napier (Pennisetum Purpureum Schum.) triturado e ração concentrada. Foi utilizado um triturador de forragem (de faca) para proceder à moagem do feno, reduzindoo a partículas com tamanho de aproximadamente um a três centímetros. Para o preparo dos concentrados experimentais foi utilizado polpa cítrica, farelo de soja, farelo de babaçu, e suplemento mineral e aditivo (98,75\% polpa cítrica e 1,25\% Rumensin ${ }^{\circledR} 100$ ). Na tabela 1, é encontrada a composição química e bromatológica dos alimentos utilizados nas dietas experimentais. 
Tabela 1 - Composição química bromatológicas dos alimentos utilizados na elaboração das rações experimentais do ensaio de Digestibilidade e Balanço Nitrogenado.

\begin{tabular}{|c|c|c|c|c|c|c|c|c|c|c|c|c|c|c|}
\hline Alimentos & $\begin{array}{c}\text { EM } \\
\left(\text { Mcal.kgMS }^{-1}\right)\end{array}$ & $\begin{array}{l}\text { MS } \\
(\%)\end{array}$ & PB & $\mathrm{EE}$ & MM & FB & ENN & $\begin{array}{r}\text { FDN } \\
(\% \mathrm{~N}\end{array}$ & $\begin{array}{l}\text { FDA } \\
\text { MS) }\end{array}$ & $\mathrm{Ca}$ & $\mathrm{P}$ & $\mathrm{Mg}$ & $\mathrm{Na}$ & K \\
\hline $\begin{array}{l}\text { Feno Capim Napier } \\
\text { (P. Purpureum Schum.) }\end{array}$ & $1,91^{2}$ & 0,918 & 9,26 & 1,58 & 5,68 & 36,74 & 46,75 & 66,25 & 41,22 & 0,39 & 0,14 & 0,33 & 0,21 & 2,04 \\
\hline Farelo de Soja & $3,15^{2}$ & 0,892 & 54,66 & 2,99 & 5,92 & 5,60 & 30,83 & 11,50 & 6,66 & 0,24 & 0,62 & 0,36 & 0,17 & 3,22 \\
\hline Farelo de Babaçu & $1,51^{1}$ & 0,958 & 14,74 & 5,65 & 2,84 & 46,51 & 30,26 & 78,58 & 51,55 & 0,19 & 0,45 & 0,26 & 0,23 & 0,86 \\
\hline Polpa Cítrica & $3,01^{2}$ & 0,916 & 5,93 & 2,32 & 5,30 & 11,95 & 74,49 & 20,33 & 13,16 & 1,56 & 0,16 & 0,12 & 0,16 & 1,41 \\
\hline Aditivo (Rumensin ${ }^{\circledR} 100$ ) & $3,01^{2}$ & 0,916 & 5,86 & 2,29 & 5,23 & 11,80 & 73,56 & 20,08 & 13,00 & 1,54 & 0,16 & 0,12 & 0,16 & 1,39 \\
\hline Mineral & - & 0,990 & - & - & - & - & - & - & - & $126^{*}$ & $72^{*}$ & $5^{*}$ & $148^{*}$ & - \\
\hline
\end{tabular}

Na tabela 2 são apresentados os fracionamentos do Nitrogênio Total (NT) de cada alimento utilizado no ensaio de Digestibili- dade segundo o sistema de fracionamento descrito por Cornell Net Carbohydrate and Protein System (CNCPS, 2004).

Tabela 2 Fracionamento do Nitrogênio Total segundo CNCPS (2004).

\begin{tabular}{|c|c|c|c|c|c|c|}
\hline Alimentos & PB & $\mathrm{A}$ & B1 & B2 & B3 & $\mathrm{C}$ \\
\hline & & & \% Nitrogên & $\mathrm{al}-\mathrm{CN}$ & (2004) & \\
\hline $\begin{array}{l}\text { Feno Capim Napier } \\
\text { (P. Purpureum Schum.) }\end{array}$ & 9,26 & 34,46 & 6,08 & 34,46 & 13,51 & 11,49 \\
\hline Farelo de Soja & 54,66 & 20,69 & 0,80 & 74,40 & 1,14 & 2,97 \\
\hline Farelo de Babaçu & 14,74 & 12,29 & 4,66 & 30,08 & 39,83 & 13,14 \\
\hline Polpa Cítrica & 5,93 & 33,68 & 8,42 & 21,05 & 23,16 & 13,68 \\
\hline Aditivo (Rumensin ${ }^{\circledR} 100$ ) & 5,86 & 33,68 & 8,42 & 21,05 & 23,16 & 13,68 \\
\hline
\end{tabular}

Os animais foram pesados no início do primeiro período de adaptação e sorteados nos tratamentos experimentais. Utilizando os pesos vivos (PV), foram calculadas as rações segundo os princípios de inclusão de proteína degradável no rúmen estabelecidos pelo Sistema Britânico AFRC (1993). Esse procedimento foi utilizado objetivando criar condições fermentativas ruminais semelhantes entre os tratamentos.

Objetivando estimar as demandas diárias de energia metabolizável, foi proposto um ganho de peso médio diário da ordem de $0,85 \%$ do PV, tomando o peso vivo inicial como referência para esta escala do ganho.

O cálculo das rações foi feito com base nos consumos voluntários avaliados durante o período de adaptação dos animais às dietas experimentais. O objetivo desse procedimento foi verificar a capacidade dos animais em ingerir os alimentos que seriam oferecidos na fase experimental, em especial à palatabilidade do farelo de babaçu.
As rações oferecidas durante o período de adaptação foram elaboradas seguindo os princípios que regeram a definição dos tratamentos, porém com parâmetros de consumo estimados.

Inicialmente foram realizadas ofertas de alimentos considerando ingestões de matéria seca (IMS) da ordem de $70 \mathrm{~g}$ por quilograma de peso metabólico $\left(70 \mathrm{~g} / \mathrm{PV}^{0,75}\right)$, as quais foram elevadas até que houvesse a estabilização da ingestão, que se situou em torno de $90 \mathrm{~g} \mathrm{MS} / \mathrm{kg} \mathrm{PV}^{0,75}$, sendo então este valor assumido para a elaboração das rações utilizadas no período experimental.

As rações experimentais foram formuladas com base no PV médio dos animais por tratamento, de acordo com os princípios do modelo AFRC (1993). Esse procedimento foi assumido para proporcionar a cada animal a condição alimentar mais aproximada aos princípios de equilíbrio fermentativo ruminal propostos pelo AFRC (1993). 
A alimentação dos animais era feita em duas refeições diárias, às 8 horas e às 15 horas. $\mathrm{O}$ volumoso e o concentrado foram ofertados 50\% pela manhã e 50\% à tarde. O fornecimento diário de alimentos considerou uma quantidade excedente de $20 \%$ de feno para permitir sobras de alimentação.

Os animais também receberam, adicionados ao concentrado, uma mistura mineral completa (macro e micro minerais) para garantir o consumo de $15 \mathrm{~g} / \mathrm{animal} /$ dia. Além disso, os animais dispunham de água limpa e fresca em tempo integral, em baldes plásticos adequados para esse propósito.

Os tratamentos foram elaborados levando em consideração níveis crescentes de inclusão de farelo de babaçu em sua ração. Para a definição dos planos dietéticos, foram consideradas condições que priorizassem o atendimento da demanda de nitrogênio no rúmen, aprimorando a síntese de proteína microbiana, em diferentes níveis de inclusão de farelo de babaçu na dieta. Dessa forma, foram elaborados quatro planos dietéticos, sendo os seguintes: níveis de inclusão de farelo de babaçu nas rações: 0\%, 7,14\%, 14,54\% e $21,70 \%$ na MS ingerida.

A proporção dos alimentos, composições nutricionais, oferta da Matéria Seca (MS), Matéria Orgânica (MO), Proteína Bruta (PB) e Matéria Mineral (MM) nas rações experimentais estão descritos na tabela 3.

Tabela 3 - Proporção dos alimentos, composições nutricionais, oferta da MS, MO, PB e MM nas rações experimentais (valores médios por tratamento) do ensaio de digestibilidade.

\begin{tabular}{|c|c|c|c|c|}
\hline Alimentos & $\mathrm{T} 1$ & $\mathrm{~T} 2$ & T3 & $\mathrm{T} 4$ \\
\hline & \multicolumn{4}{|c|}{ (\%MS) - Primeira Rodada } \\
\hline $\begin{array}{l}\text { Feno Capim Napier } \\
\text { (P. Purpureum Schum.) }\end{array}$ & 32,52 & 31,84 & 31,19 & 30,50 \\
\hline Farelo de Soja & 25,12 & 23,51 & 21,97 & 20,44 \\
\hline Farelo de Babaçu & 0,000 & 7,32 & 14,50 & 21,66 \\
\hline Polpa Cítrica & 39,97 & 34,02 & 29,13 & 24,21 \\
\hline Aditivo (Rumensin ${ }^{\circledR} 100$ ) & 1,62 & 1,59 & 1,56 & 1,52 \\
\hline Mineral & 1,75 & 1,72 & 1,68 & 1,64 \\
\hline OMS (g/dia) & 1129 & 1153 & 1177 & 1204 \\
\hline OMO (g/dia) & 1047 & 1072 & 1097 & 1124 \\
\hline PB (\% MS $)_{\text {oferta }}$ & 19,16 & 19,00 & 18,86 & 18,73 \\
\hline $\mathrm{IPB}_{\text {F.babaçu }}(\% \mathrm{IPB})$ & 0,00 & 5,68 & 11,33 & 17,05 \\
\hline $\mathrm{MM}(\% \mathrm{MS})_{\text {oferta }}$ & 7,24 & 7,01 & 6,79 & 6,57 \\
\hline
\end{tabular}

\begin{tabular}{|c|c|c|c|c|}
\hline Alimentos & T1 & $\mathrm{T} 2$ & T3 & $\mathrm{T} 4$ \\
\hline & \multicolumn{4}{|c|}{ (\%MS) - Segunda Rodada } \\
\hline $\begin{array}{l}\text { Feno Capim Napier } \\
\text { (P. Purpureum Schum })\end{array}$ & 32,68 & 31,94 & 31,30 & 30,62 \\
\hline Farelo de Soja & 25,17 & 23,62 & 22,06 & 20,50 \\
\hline Farelo de Babaçu & 0,000 & 7,36 & 14,58 & 21,75 \\
\hline Polpa Cítrica & 39,10 & 34,05 & 29,15 & 24,24 \\
\hline Aditivo (Monensina $\mathrm{Na}$ ) & 1,47 & 1,44 & 1,41 & 1,49 \\
\hline Mineral & 1,59 & 1,55 & 1,52 & 1,49 \\
\hline OMS (g/dia) & 1247 & 1276 & 1302 & 1331 \\
\hline OMO (g/dia) & 1150 & 1169 & 1197 & 1227 \\
\hline PB (\% MS $)_{\text {oferta }}$ & 19,20 & 19,07 & 18,92 & 18,78 \\
\hline $\mathrm{IPB}_{\text {F.babaçu }}(\% \mathrm{IPB})$ & 0,00 & 5,69 & 11,36 & 17,07 \\
\hline $\mathrm{MM}(\% \mathrm{MS})_{\text {oferta }}$ & 7,08 & 6,86 & 6,64 & 6,42 \\
\hline
\end{tabular}

Legendas:

OMS: oferta de matéria seca ( $\mathrm{g} /$ dia);

OMO: oferta de matéria orgânica (g/dia);

PB: concentração de proteína bruta da dieta (\% MS);

$\mathrm{IPB}_{\mathrm{F} \text {.Babaçu }}$ : ingestão de proteína bruta proveniente do babaçu (\% PB);

MM: concentração da matéria mineral da dieta (\% MS). 
Os alimentos eram pesados antes de ofertados aos animais. Diariamente, as sobras eram recolhidas antes do fornecimento da refeição matutina, pesadas, amostradas e acondicionadas em sacos plásticos devidamente identificados.

As fezes e a urina totais foram recolhidas diariamente, pela manhã. Seus pesos foram anotados, foram amostradas $(20 \%$ do total diário) e, acondicionadas em sacos plásticos devidamente identificados e congeladas para posteriores análises químico-bromatológicas. A urina produzida por cada animal teve seu volume $(\mathrm{mL})$ também registrado e foi também efetuada amostragem (20\% do volume diário), sendo a amostra acondicionada em garrafas de vidro âmbar devidamente identificadas.

A determinação da primeira matéria pré-seca dos alimentos foi feita com a secagem das amostras após a pesagem. Essas amostras foram secas em estufa ventilada a $55^{\circ} \mathrm{C}$ por 48 horas, pesadas e em seguida moídas em moinho tipo Willey com peneira de um (01) $\mathrm{mm}$.

Todas as amostras de alimentos e de sobras foram analisadas para determinação da MS total e da PB segundo as metodologias descritas por Silva e Queiroz (2002). Também foram determinadas as concentrações de fibras insolúveis em detergente neutro (FDN) e detergente ácido (FDA), segundo os procedimentos recomendados por Goering e Van Soest (1970), e foi efetuado o fracionamento da PB de todas as amostras (alimentos e sobras) segundo metodologias descritas por Malafaia e Vieira (1997) para as frações nitrogenadas segundo CNCPS (2004).

Para a determinação da matéria préseca das fezes e de seu teor de cinzas nos dois tratamentos, os mesmos procedimentos adotados para as sobras de alimentos foram também adotados para as fezes dos animais.

Os valores de digestibilidade aparente $\left(\mathrm{D}_{\mathrm{ap}}\right)$ da MS, MO, foram obtidos pela fórmula proposta por Silva e Leão (1979):

$$
D_{\text {ap }}=\frac{[(\text { ING } \times \% \text { ING })-(\text { SOB } \times \% \text { SOB })]-(\text { FEZ } \times \% \text { FEZ }) \times 100}{(\text { ING } \times \% \text { ING })-(\text { SOB } \times \% \text { SOB })}
$$

Onde:

ING = quantidade de alimento fornecido;

$\%$ ING $=$ teor do nutriente no alimento fornecido;

$\mathrm{SOB}=$ quantidades de sobras retiradas;

$\% \mathrm{SOB}=$ teor do nutriente nas sobras;

FEZ = quantidade de fezes coletadas;

$\% \mathrm{FEZ}=$ teor do nutriente nas fezes.

O balanço de $\mathrm{N}$ é obtido subtraindo-se o total de $\mathrm{N}$ excretado nas fezes e na urina do total de $\mathrm{N}$ ingerido, representando o total de $\mathrm{N}$ que efetivamente ficou retido no organismo animal:

N RETIDO $(\mathbf{N R})=($ N Fornecido $-\mathrm{N}$ Sobras $)$ - (N Fezes + Urina)

Os valores obtidos a partir da subtração do total de $\mathrm{N}$ ingerido, menos o $\mathrm{N}$ contido nas fezes, referem-se ao $\mathrm{N}$ absorvido:

N ABSORVIDO (NA) $=(\mathrm{N}$ Fornecido $-\mathrm{N}$ Sobras) - N Fezes

O delineamento experimental foi em blocos casualizados, com quatro tratamentos e seis repetições, sendo os blocos definidos como períodos.

As médias foram submetidas ao Teste de Normalidade Shapiro-Wilk e comparadas entre si pelo Teste de Tukey a $5 \%$ de probabilidade. $\mathrm{O}$ teste de normalidade foi realizado segundo os procedimentos do programa estatístico "ASSISTAT", e a comparação de médias foi realizada utilizando o programa estatístico "SISVAR".

\section{Modelo estatístico:}

$Y i j k=\bar{m}+T i+B j+E i j k$

em que:

Yijk = observação na dieta $\mathbf{i}$, com o bloco $\mathbf{j}$ e na repetição $\mathbf{k}$.

$\overline{\mathbf{m}}=$ média geral.

$\mathbf{T i}=$ efeito tratamento.

Bj = efeito bloco "j".

Eijk = erro experimental. 


\section{Resultados e discussão}

2.1 Ingestão de Matéria Seca (IMS), Digestibilidade aparente da Matéria Seca $\left(\mathrm{D}_{\mathrm{ap}} \mathrm{MS}\right)$ e Digestibilidade aparente da Matéria Orgânica (DapMO)
Na tabela 4 são apresentados os dados referentes à ingestão de MS (IMS), à Digestibilidade aparente da MS ( $\left.\mathrm{D}_{\mathrm{ap}} \mathrm{MS}\right)$ e à Digestibilidade aparente da $\mathrm{MO}\left(\mathrm{D}_{\mathrm{ap}} \mathrm{MO}\right)$ para os tratamentos experimentais.

Tabela 4 - Inclusão de Farelo de Babaçu (\% ração), ingestão de matéria seca (IMS), Digestibilidade aparente da matéria seca $\left(\mathrm{D}_{\mathrm{ap}} \mathrm{MS}\right)$ e da matéria orgânica $\left(\mathrm{D}_{\mathrm{ap}} \mathrm{MO}\right)$.

\begin{tabular}{cccc}
\hline $\begin{array}{c}\text { Inclusão F. de Babaçu } \\
\text { (\% ração) }\end{array}$ & IMS $\left(\mathbf{g} / \mathbf{k g}^{0,75}\right)$ & $\mathbf{D}_{\text {ap }} \mathbf{M S}(\%)$ & $\mathbf{D}_{\text {ap }} \mathbf{M O}(\%)$ \\
$0 \%$ & $0,084 \mathrm{~b}$ & $61,77 \mathrm{a}$ & $65,29 \mathrm{a}$ \\
$7,34 \%$ & $0,089 \mathrm{ab}$ & $57,39 \mathrm{a}$ & $60,30 \mathrm{ab}$ \\
$14,54 \%$ & $0,089 \mathrm{ab}$ & $58,27 \mathrm{a}$ & $64,18 \mathrm{ab}$ \\
$21,70 \%$ & $0,092 \mathrm{a}$ & $58,09 \mathrm{a}$ & $59,70 \mathrm{~b}$ \\
\hline Blocos & $0,089 \mathrm{a}$ & $59,45 \mathrm{a}$ & $62,30 \mathrm{a}$ \\
1 Rodada & $0,087 \mathrm{a}$ & $58,30 \mathrm{a}$ & $62,44 \mathrm{a}$ \\
2 Rodada & 4,24 & 4,57 & 5,38 \\
\hline CV(\%) & &
\end{tabular}

Médias seguidas de mesma letra minúscula na coluna não diferem entre si pelo teste de Tukey a $5 \%$ de probabilidade.

Foi observada que a IMS tendeu a aumentar com a adição do farelo de babaçu nas rações experimentais, sendo observada diferença $(p<0,05)$ entre os níveis $0 \%$ e $21,70 \%$ de inclusão de farelo de Babaçu na ração. Essa observação também foi evidenciada com a análise de regressão linear simples entre as duas variáveis (Figura 1). Observou-se que, apesar de apresentar um $R^{2}$ relativamente baixo, devido à baixa participação do farelo de babaçu na ração, o ajuste de regressão foi significativo $(p<0,05)$ para as variáveis, evidenciando um comportamento diretamente proporcional entre elas.
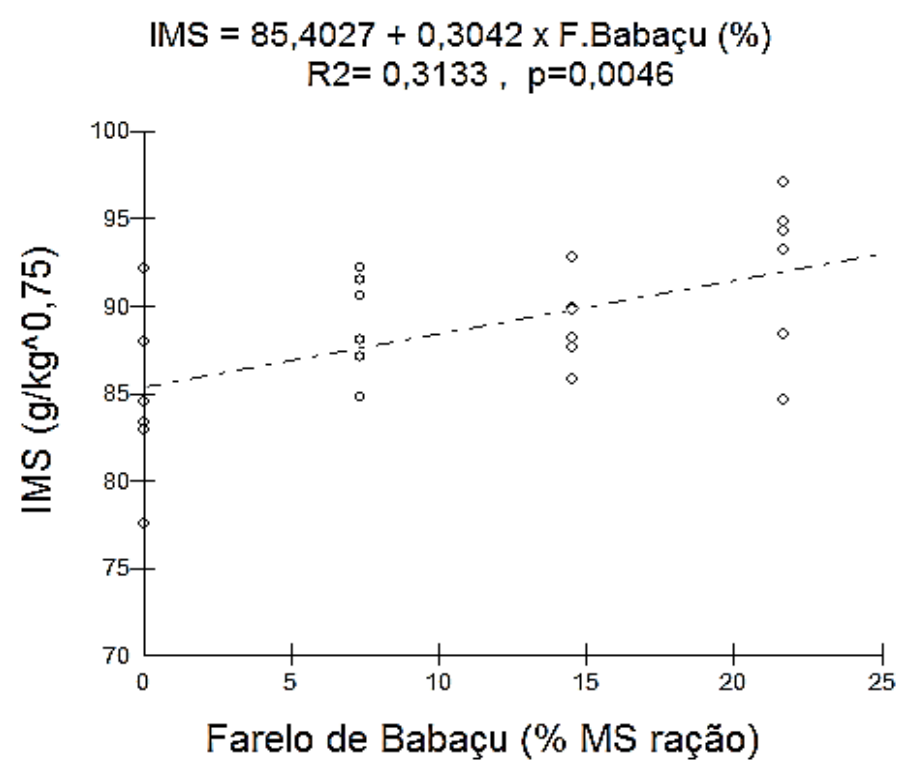

Figura 1 - Regressão linear simples entre a ingestão de matéria seca (IMS) e os níveis de inclusão de farelo de babaçu. 
A comparação de médias obtidas pelo teste Tukey ( $5 \%$ probabilidade), evidenciou um aumento significativo $(\mathrm{p}<0,05)$ para a IMS apenas entre o nível $0 \%$ e 21,70\% de inclusão de farelo de babaçu na ração. Esse comportamento divergiu do observado por Castro (2012) em que a IMS e IMO em g/dia, \%PV e g/UTM não foram alterados ( $p>0,05)$ com a inclusão de torta de babaçu nas dietas. Por outro lado, Xenofonte et al. (2008) verificaram efeito linear decrescente $(p<0,05)$ dos níveis de farelo de babaçu sobre o consumo de matéria seca (CMS) em g/dia. Segundo Miotto et al. (2012), os CMS; CMO e CPB, expressos em g $\mathrm{dia}^{1}$, \% PV e g $\mathrm{UTM}^{-1}$, não foram alterados pela inclusão de farelo de mesocarpo de babaçu às dietas. Diante da divergência de observações descritas na literatura, deve-se buscar evidenciar para cada caso quais foram as causas que induziram comportamentos diferentes entre os ensaios.

Os fatores que regulam o consumo em ruminantes são diversos e complexos, variando desde fatores intrínsecos aos alimentos a aspectos intrínsecos aos animais, podendo estar ligado simultaneamente aos dois fatores e, além disso, ser condicionado pelo manejo alimentar. Procurou-se assim, uma evidência nos dados que sugerisse uma potencial causa para a maior IMS no maior nível de inclusão de farelo de babaçu na ração. Para tanto, a observação das análises de regressão linear simples foram úteis para se postular uma potencial explicação.

Nas figuras 2 e 3 estão apresentados os ajustes de regressão linear simples entre $\mathrm{D}_{\mathrm{ap}} \mathrm{MS}$ e $\mathrm{D}_{\mathrm{ap}} \mathrm{MO}$ para os níveis de inclusão de farelo de babaçu nas rações, respectivamente. Uma observação cuidadosa da figura 3 evidencia que o ajuste de regressão não foi significativo $(p>0,05)$ pela maior variabilidade dos dados. Entretanto um comportamento que chama a atenção na figura 03, é o da maior distribuição dos dados em função dos níveis de inclusão de farelo de babaçu nas rações. Observou-se que, para o tratamento com $0 \%$ de inclusão de farelo de babaçu, houve maior homogeneidade entre as estimativas de $\mathrm{D}_{\mathrm{ap}} \mathrm{MO}$ quando comparada às variações observadas para os planos nutricionais que apresentavam o farelo de babaçu na formulação. Pode-se dizer assim que, para as rações que apresentavam o farelo de babaçu, observou-se maior variabilidade nos dados entre repetições, possivelmente por induzir um comportamento de maior seletividade à ração ofertada, o que justificaria a maior variabilidade na digestibilidade aparente da matéria orgânica observada entre as rações.
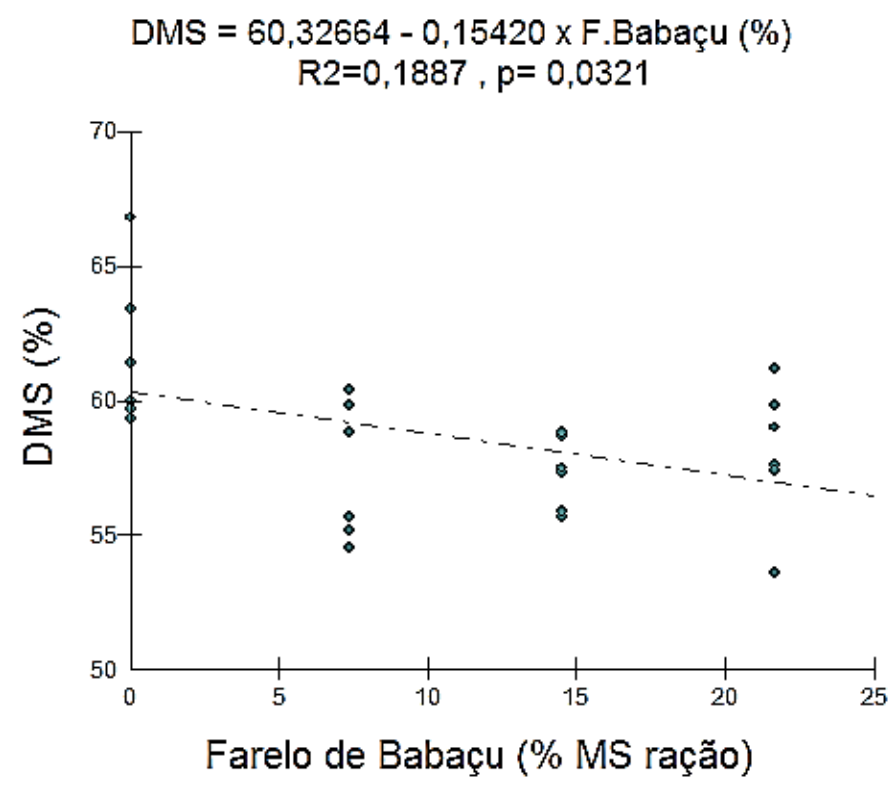

Figura 2 - Regressão linear simples entre a Digestibilidade aparente da Matéria Seca $\left(\mathrm{D}_{\mathrm{ap}} \mathrm{MS}\right)$ e os níveis de inclusão de farelo de babaçu nas rações experimentais. 


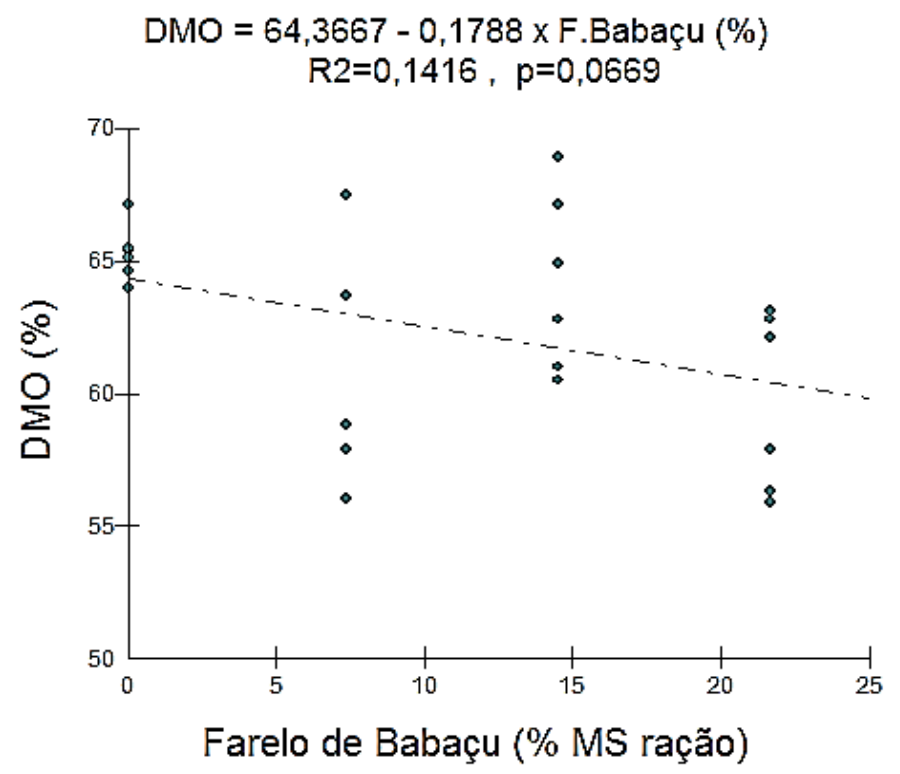

Figura 3 - Regressão linear simples entre a Digestibilidade aparente da Matéria Orgânica $\left(D_{a p} M O\right)$ e os níveis de inclusão de farelo de babaçu nas rações experimentais.

Em outras palavras, a presença do farelo de babaçu pode ter causado maior seletividade devido à sua baixa palatabilidade. Assim, o comportamento de aumento de IMS reportado na literatura pode estar vinculado à maior seletividade ao consumo e não à maior palatabilidade do farelo de babaçu.

Essa suposição se respalda no fato de que a o ajuste de regressão linear simples entre $\mathrm{D}_{\mathrm{ap}} \mathrm{MO}$ e níveis de farelo de babaçu não foi significativa $(p>0,05)$ e apresentou um comportamento bastante discrepante para a variabilidade dentro dos tratamentos.

Castro (2012), estudando dietas com inclusão de torta de babaçu, reportou que, ao utilizar maiores níveis de torta de babaçu em dietas para ovinos, os animais manifestaram maior consumo de volumoso, visto que a dieta era fornecida na forma de mistura completa, e as sobras recolhidas nos cochos continham, proporcionalmente, maiores quantidades de torta de babaçu do que de feno. A autora comenta ainda que esse comportamento seletivo pode ter ocorrido com o objetivo de aumentar o consumo de fibra longa, ou por menor palatabilidade da torta quando comparada à do feno de tifton-85 utilizado no experimento. Assim, conclui que o farelo do coco babaçu pode substituir até $35 \%$ o feno de tifton- 85 na dieta de ovinos sem que haja prejuízo no consumo e na digestibilidade da matéria seca, devendo-se adicionar alimentos palatáveis para aumentar a aceitação dos animais pela torta de babaçu.

Uma vez analisados os efeitos observados para a variável ingestão de MS, podese discutir os parâmetros $\mathrm{D}_{\mathrm{ap}} \mathrm{MS}$ e $\mathrm{D}_{\mathrm{ap}} \mathrm{MO}$ (Tabelas 5 e 6). Para a $D_{\text {ap }}$ MS, foi observada diferença $(p>0,05)$ entre as rações experimentais, porém, foi observada diferença $(p<0,05)$ para a $\mathrm{D}_{\mathrm{ap}} \mathrm{MO}$ mesmo com um Coeficiente de Variação $\mathrm{CV}(\%)$ mais alto. O que pode ser justificado pelo fato de as variações dentro dos tratamentos terem sido maiores para a $\mathrm{D}_{\mathrm{ap}} \mathrm{MO}$ do que para as observadas na $\mathrm{D}_{\mathrm{ap}} \mathrm{MS}$. 
Tabela 5 - Resumo da análise de variância para a Digestibilidade aparente da Matéria Seca $\left(\mathrm{D}_{\mathrm{ap}} \mathrm{MS}\right)$ - Ensaio de Digestibilidade e Balanço Nitrogenado. Variável analisada: DMS Opção de transformação: Variável sem transformação $(Y)$

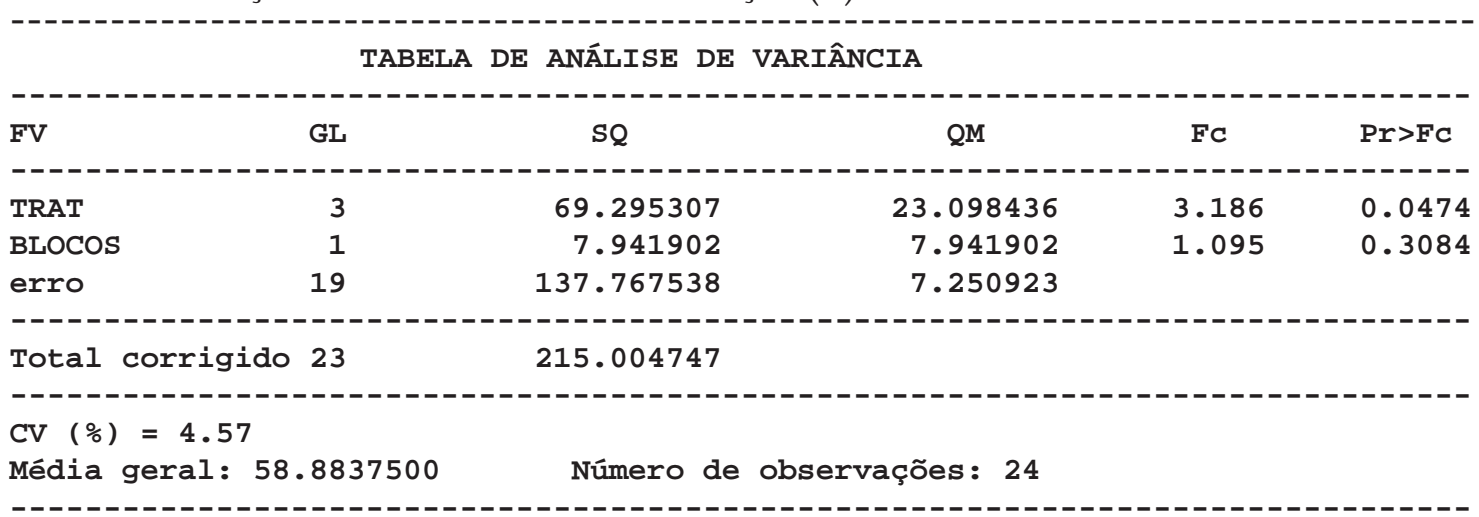

Tabela 6 - Resumo da análise de variância para a Digestibilidade aparente da Matéria Orgânica $\left(\mathrm{D}_{\mathrm{ap}} \mathrm{MO}\right)$ - Ensaio de Digestibilidade e Balanço Nitrogenado. Variável analisada: DMO - Opção de transformação: Variável sem transformação $(Y)$

TABELA DE ANÁLISE DE VARIÂNCIA

\begin{tabular}{|c|c|c|c|c|c|}
\hline FV & GL & SQ & QM & Fc & $\mathrm{Pr}>\mathrm{Fc}$ \\
\hline TRAT & 3 & 139.154740 & 46.384913 & 4.125 & 0.0207 \\
\hline BLOCOS & 1 & 0.124416 & 0.124416 & 0.011 & 0.9173 \\
\hline erro & 19 & 213.639716 & 11.244196 & & \\
\hline Total corrigido & 23 & 352.918872 & & & \\
\hline 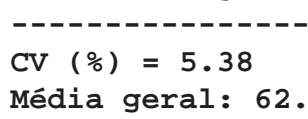 & & Número de ob & es: 24 & & \\
\hline
\end{tabular}

Uma vez que foi identificada diferença $(\mathrm{p}<0,05)$ na comparação entre médias para a DMO das rações, pode-se dizer que a inclusão do farelo de babaçu reduziu a digestibilidade da MO evidenciando um efeito inversamente proporcional do farelo de babaçu sobre as rações experimentais. Este comportamento foi evidenciado no ajuste de regressão entre a $\mathrm{D}_{\text {ap }}$ MS e o nível de inclusão de babaçu nas rações, sendo significativo o ajuste de regressão. A reduzida participação do farelo de babaçu nas dietas experimentais explica o baixo coeficiente de determinação para a regressão, mas nos permite estimar a digestibilidade do farelo de babaçu para o nível de $100 \%$.

A partir da equação de regressão apresentada na figura 2, estimou-se a $\mathrm{D}_{\text {ap }} \mathrm{MS}$ para o farelo de babaçu, obtendo-se o valor de $44,90 \%$. Como o ajuste de regressão da DMO não foi significativo, a estimativa da DMO foi obtida fazendo-se um paralelo entre a média geral da DMO e DMS observadas no ensaio experimental.

Observou-se neste ensaio experimental que a $\mathrm{D}_{\mathrm{ap}} \mathrm{MS}$ da dieta foi $94,40 \%$ da observada para a MO. Assim, dividindo-se a $\mathrm{D}_{\mathrm{ap}} \mathrm{MS}$ calculada para o farelo de babaçu $(44,90 \%)$ por 0,9440 , pode-se estimar a $\mathrm{D}_{\text {ap }} \mathrm{MO}$ deste alimento. Obteve-se assim, a estimativa do valor da $\mathrm{D}_{\mathrm{ap}} \mathrm{MO}$ do farelo de babaçu calculado como $47,56 \%$.

Conforme relatado na publicação do National Library of Australia Cataloguing in Publication entry Nutrient requirements of domesticated ruminants (CSIRO, 2007), os métodos mais utilizados para predição do valor energético dos alimentos são realizados através da determinação da DMS e DMO. Ainda nesta publicação, é citada a equação de regressão de Terry et al. (1974) para a determinação do valor energético da $\mathrm{MO}$ digestível obtida a partir de uma grande bi- 
blioteca de alimentos tropicais, expressa em $\mathrm{MJ} / \mathrm{kg}$, como segue:

$$
\left[\mathrm{D}_{\mathrm{ap}} \mathrm{MO}\right]_{\mathrm{MJ} / \mathrm{kg}}=17,33+0,0124 \cdot[\mathrm{PB}]_{\mathrm{g} / \mathrm{kgMS}}
$$

A partir da referida equação descrita por Terry et al. (1974), estimou-se a concentração energética da $\mathrm{MO}$ digestível do farelo de babaçu a partir de sua concentração de PB, obtendo o resultado de 19,16 MJ/kg. Assim, cada quilograma de MS de farelo de babaçu apresenta $47,56 \%$ digestibilidade para a fração orgânica, o que equivale a 9,11 MJ/kg MS de energia digestível. Assim, multiplicando-se o valor de $9,11 \mathrm{MJ} / \mathrm{kg}$ MS por 0,81 , conversão de energia digestível em energia metabolizável segundo AFRC (1993), obteve-se o valor de $7,38 \mathrm{MJ} / \mathrm{kg}$ MS o que equivale a $1,76 \mathrm{Mcal} /$ $\mathrm{kg}$ MS ou $48,78 \%$ de NDT.

Burgi (1995, citado por TEIXEIRA et al., 2007), reportou para o bagaço de cana in natu$r a$ (BIN) um valor de NDT de $44,72 \%$ e, para o bagaço de cana auto-hidrolisado (BAH), $55,41 \%$. Sendo assim o farelo de coco babaçu, conforme os dados obtidos no presente experimento, teria valor intermediário de NDT comparado ao BIN e o BAH. Esses resultados para o valor energético do farelo de babaçu são corroborados pelos autores Rocha Júnior et al. (2003) e Xenofonte et al. (2008 e 2009), que, utilizando a equação de Weiss (1999), estimaram um valor de NDT de $49,38 \%$ para o farelo de babaçu. De acordo com Valadares Filho et al. (2000/2001, citado por SILVA,
2006), a torta de babaçu apresenta 1,75 Mcal/ Kg de energia metabolizável, confirmando os valores obtidos neste experimento.

Souza Júnior et al. (2002) verificaram que, até $20 \%$, o farelo de babaçu em dietas para ovinos não afetou o desempenho dos animais, mas, com a inclusão de $30 \%$, houve uma perda no ganho de peso em relação às dietas à base de milho e farelo de soja.

Silva (2006) afirma que o farelo de coco babaçu atendeu tanto as necessidades de mantença como a produção dos animais, demonstrando positivamente a relação custobenefício. Em contraste às observações de Silva (2006), os resultados do presente ensaio, evidenciam que o farelo de babaçu tem baixo potencial energético o que restringe sua inclusão em dietas para animais em produção. Já a viabilidade econômica de seu uso na alimentação dos ruminantes é dependente primeiramente do custo desse subproduto, posteriormente do nível de inclusão dele na dieta, do nível de produção esperado para a espécie animal e do valor econômico da carne produzida.

\subsection{Balanço Nitrogenado (BN)}

Na Tabela 7, constam os resultados obtidos no estudo do balanço de nitrogênio aferido para os tratamentos. O balanço referese ao nitrogênio retido (NR) após terem sido subtraídas, do montante ingerido, as quantidades excretadas vias fezes e urina.

Tabela 7 - Resultados do balanço de nitrogênio verificados para os tratamentos no ensaio de Digestibilidade.

\begin{tabular}{|c|c|c|c|c|c|c|c|c|}
\hline $\begin{array}{l}\text { Percentuais de F. } \\
\text { De Babaçu nas } \\
\text { rações (TRAT) }\end{array}$ & $\begin{array}{c}\mathrm{N} \\
\text { inger. }\end{array}$ & $\begin{array}{c}N \\
\text { fezes }\end{array}$ & $\begin{array}{c}\mathbf{N} \\
\text { absorv. }\end{array}$ & $\begin{array}{l}\mathbf{N} \text { absv./ } \\
\mathbf{N} \text { inger. }\end{array}$ & $\begin{array}{c}\mathbf{N} \\
\text { urina }\end{array}$ & $\begin{array}{c}\mathrm{N} \\
\text { retido }\end{array}$ & $\begin{array}{c}\mathbf{N} \text { ret./ } \\
\mathbf{N} \\
\text { inger. }\end{array}$ & $\begin{array}{l}\text { N ret./N } \\
\text { absorv. }\end{array}$ \\
\hline & (g/dia) & (g/dia) & (g/dia) & $(\%)$ & (g/dia) & (g/dia) & $(\%)$ & $(\%)$ \\
\hline $0 \%$ & $34,49 a$ & $11,04 \mathrm{a}$ & $23,44 \mathrm{a}$ & $67,65 \mathrm{a}$ & $9,81 \mathrm{a}$ & $13,63 \mathrm{a}$ & $39,42 \mathrm{a}$ & 57,65 a \\
\hline $7,14 \%$ & 34,85 a & $10,13 \mathrm{a}$ & $24,72 \mathrm{a}$ & $70,90 \mathrm{a}$ & $8,08 \mathrm{a}$ & 16,63 a & $48,07 \mathrm{a}$ & 67,77 a \\
\hline $14,54 \%$ & $35,70 \mathrm{a}$ & $9,89 \mathrm{a}$ & $25,80 \mathrm{a}$ & 72,31 a & $7,30 \mathrm{a}$ & $18,50 \mathrm{a}$ & $52,14 \mathrm{a}$ & $71,90 \mathrm{a}$ \\
\hline $\begin{array}{c}21,70 \% \\
\text { (Blocos) }\end{array}$ & 35,13 a & $11,21 \mathrm{a}$ & $23,92 \mathrm{a}$ & $68,12 \mathrm{a}$ & $8,34 \mathrm{a}$ & $15,57 \mathrm{a}$ & $44,42 \mathrm{a}$ & 65,09 a \\
\hline Rodada 1 & $34,24 \mathrm{~A}$ & $10,17 \mathrm{~A}$ & $24,06 \mathrm{~A}$ & 70,29 A & $4,68 \mathrm{~A}$ & $19,38 \mathrm{~A}$ & $56,56 \mathrm{~A}$ & $80,44 \mathrm{~A}$ \\
\hline Rodada 2 & $35,85 \mathrm{~B}$ & $10,96 \mathrm{~A}$ & $24,88 \mathrm{~A}$ & $69,20 \mathrm{~A}$ & $12,09 \mathrm{~B}$ & $12,79 \mathrm{~B}$ & $35,46 \mathrm{~B}$ & 50,77 B \\
\hline CV (\%) & 2,24 & 11,23 & 8,81 & 5,92 & 32,50 & 19,42 & 17,94 & 16,61 \\
\hline
\end{tabular}

- Médias de tratamentos seguidas de mesma letra minúscula para tratamentos e maiúsculas para blocos não diferem entre si pelo teste de Tukey com nível de significância de 5\%. CV (\%) coeficiente de variação.

- Nomenclatura: Nitrogênio (N) ingerido (inger.); excretado nas fezes (fezes); absorvido (absorv.); excretado na urina (urina); retido (retido); retido em relação ao ingerido (ret./inger.); retido em relação ao absorvido (ret./ absorv.). 
Primeiramente é importante considerar que, entre a primeira e segunda rodada do experimento, foi realizado um ajuste na oferta de alimentos em função dos pesos dos animais nos respectivos tratamentos e do ganho de peso esperado para o período. Entretanto não foi observado efeito dos tratamentos $(p>0,05)$ sobre todas as variáveis consideradas no BN, evidenciando uma homogeneidade de condição metabólica entre os percentuais de inclusão de babaçu estudados.

Foi observado aumento na excreção nitrogenada urinária $(p<0,05)$, entre rodadas. Esse aumento não se justifica apenas pela diferença no aumento do consumo de nitrogênio na segunda rodada, mas sim, por um aumento nas perdas de nitrogênio urinário oriundo do metabolismo secundário dos animais. Esse aumento da perda de nitrogênio urinário pode ser decorrente de uma condição de estresse dos animais submetidos ao manejo em gaiolas metabólicas. Tal situação de estresse pode condicionar uma redução no ganho de peso e consequentemente na sobra nitrogenada no metabolismo secundário.

Outra importante observação pode ser feita através da relação do NR sobre o NA. Por esse índice, pode-se avaliar a qualidade das proteínas de uma dieta, pois expressa a fração percentual digerida que é utilizada pelo corpo do animal (HUNTINGTON; ARCHIBEQUE, 1999). Esse parâmetro indica que, entre os níveis estudados de utilização de farelo de babaçu na dieta de ovinos, não houve efeito $(p>0,05)$ negativo desse alimento sobre o $\mathrm{BN}$. Porém, cabe ressaltar que esse equilíbrio não pode ser garantido apenas pelo nível de inclusão do farelo de babaçu na dieta, mas também, deve ser considerado a influência que o nível de desempenho animal exerce sobre a exigência proteica dos animais, além da participação que o farelo de babaçu tem sobre a ingestão de PB total da dieta.

\section{Conclusão}

Com os estudos realizados, que teve como finalidade avaliar a inclusão de níveis crescentes de farelo de babaçu na alimentação de ruminantes, conclui-se que, o farelo de babaçu apresenta um valor nutricional relativamente baixo para a alimentação de ruminantes, especificamente em termos energé- ticos, quando comparado a outros alimentos comumente utilizados em rações para esses animais. Sua utilização, quando conveniente, deverá restringir-se a baixos níveis de inclusão na dieta (não excedendo $20 \%$ da IMS), sob pena de redução da digestibilidade e da produtividade animal.

Para os níveis de inclusão estudados, o balanço nitrogenado não foi afetado pela inclusão do farelo de babaçu nas dietas.

Sugere-se desenvolvimento de projetos sobre a logística de distribuição e custo de produção do farelo do coco babaçu na indústria, além da determinação das necessidades de processamento deste subproduto (em nível de fazenda) para determinação do custo final deste e sua utilização na nutrição animal.

\section{Referências}

AGRICULTURAL AND FOOD RESEARCH COUNCIL - AFRC. Energy and protein requeriments of ruminants. Wallingford: CAB International, 1993. 159p.

CANNAS, A.; TEDESCHI, L. O.; FOX, D. G.; PELL, A. N.; VAN SOEST, P. J. A. Mechanistic model for predicting the nutrient requeriments and feed biological values for sheep. Journal of Animal Science, Champaign, v. 82, n. 1, p. 149-169, 2004.

CASTRO, K. J. Torta de babaçu: consumo, energia metabolizável, energia líquida e produção de metano em ruminantes. 2012. 89p. Tese (Doutorado em Nutrição Animal) - Departamento de Zootecnia, Escola de Veterinária da Universidade Federal de Minas Gerais - UFMG, Belo Horizonte, MG, 2012. Disponível em: <http://www.bibliotecadigital.ufmg.br/dspace/bitstream/handle/1843/VETD-8SDP7Y/tesekelvia_imprimir.pdf;jsessionid=849569F1DF9B4C9665D5822 43A408F80?sequence $=1>$. Acesso em: $1^{\circ} \mathrm{dez}$. 2012, às $14 \mathrm{~h}$.

CORNELL Net Carbohydrate and Protein System CNCPS. New York, EUA: Cornell University - Department of Animal Science, 2004. Disponível em: <http:/ / www. cncps. cornell.edu/>.

CSIRO PUBLISHING. National Library of Australia Cataloguing-in-Publication entry Nutrient requirements of domesticated ruminants. Austrália, 2007. 296p.

GOERING, H. K.; VAN SOEST, P. J. Forage fiber analysis (apparatus, reagents, procedures and some applications). Washington: USDA/ARS, 1970. 379p.

GOLDEMBERG, J.; MOREIRA, J. R. Política energética no Brasil. Estudos avançados, São Paulo, v. 19, n. 55, p. 215-228, 2005.

HUNTINGTON, G. B.; ARCHIBEQUE, S. L. Pratical aspects of urea e ammonia metabolismo in ruiminants. In: American Society of Animal Science. Proceedings... North Carolina, EUA: North Carolina State University, 1999.

MALAFAIA, P. A. M.; VIEIRA, R. A. M. Técnicas de de- 
terminação e avaliação dos compostos nitrogenados em alimentos para ruminantes. In: SIMPÓSIO INTERNACIONAL DE DIGESTIBILIDADE EM RUMINANTES, 1997, Lavras, MG. Anais... Lavras: UFLA, 1997. p. 29-54.

MIOTTO, F. R. C.; RESTLE, J.; NEIVA, J. N. M.; MACIEL, R. P.; FERNANDES, J. R. Consumo e digestibilidade de dietas contendo níveis de farelo do mesocarpo de babaçu para ovinos. Revista Ciência Agronômica, Fortaleza, CE, v. 43, n. 4, p. 792-801, 2012. Disponível em: <http://www.ccarevista.ufc.br/seer/index.php/ ccarevista/article/viewFile/1724/760>. Acesso em: $1^{\circ}$ dez. 2012, às 17h57min.

PASCOAL, L. A. F.; BEZERRA, A. P. A.; GONÇALVES, J. S. Farelo de babaçu: valor nutritivo e utilização na alimentação animal. Revista Eletrônica Nutritime, v. 3, n. 4, p. 339-345, jul./ago. 2006.

ROCHA JÚNIOR, V. R.; VALADARES FILHO, S. C., BORGES, A. M.; MAGALHÃES, K. A.; FERREIRA, C. C.B.; VALADARES, R. F. D.; PAULINO, M. F. Determinação do valor energético de alimentos para ruminantes pelo sistema de equações. Revista Brasileira de Zootecnia, Viçosa, MG, v. 32, n. 2, p. 473-479, mar./abr. 2003.

SILVA, D. J.; QUEIROZ, A. C. de. Análises de alimentos: métodos químicos e biológicos. Viçosa, MG: UFV, 2002. 235p.

SILVA, J. F. C. da; LEÃO, M. I. Fundamentos de nutrição dos ruminantes. Piracicaba, SP: Livroceres, 1979. 380p.

SILVA, T. C. P. Substituição do farelo de trigo pela torta de babaçu na alimentação de vacas mestiças em lactação. 2006. 30p. Dissertação (Mestrado em Zootecnia) - Universidade Federal Rural de Pernambuco, Recife, PE, 2006. Disponível em: <ww2.ufrpe.br/ pergamum/biblioteca/index.php.posicao_dados_acervo; http://200.17.137.108/ tde busca/arqui vo.php?codArquivo=20>. Acesso em: 12 dez. 2012, às 12h46min.

SOUZA JÚNIOR, A.; OLIVEIRA, M. E.; LOPES, J. B.; GIRÃO, R. N.; NASCIMENTO, M. P. S. B.; ARAUJO, D. L. Efeito da substituição parcial do farelo de soja e de milho por farelo de babaçu na terminação de ovinos em confinamento. In: REUNIÃO DA SOCIEDADE BRASILEIRA DE ZOOTECNIA, 39. Anais..., Recife, PE, 2002.

TEIXEIRA, F. A.; PIRES, A. V.; NASCIMENTO, P. V. N. Bagaço de cana-de-açúcar na alimentação de bovinos. REDVET®. Revista electrónica de Veterinária, v. VIII, n. 6, p. 09, 2007. Disponível em: <http:/ / www.veterinaria. org/revistas/redvet/n060607/060708.pdf>. Acesso em: 10 dez. 2012, às $14 \mathrm{~h}$.

TERRY, R. A.; OSBOURNE, D. F.; FENTON, J. S. In vitro digestibility and the estimation of energy in herbage. In: PROC 5TH GEN. MTG. EUR. GRASSLD. FED., Vaxtodling 28, p. 19-25, 1974.

WEISS, W. P. Energy prediction equations for ruminant feeds. In: CORNELL NUTRITION CONFERENCE FOR FEED MANUFACTURERS, 61., 1999. Proceedings... Ithaca: Cornell University, 1999. p 176-185.

XENOFONTE, A. R. B.; CARVALHO, F. F. R.; BATISTA, A. M. V.; MEDEIROS, G. R.; ANDRADE, R. P. X. Desempenho e digestibilidade de nutrientes em ovinos alimentados com rações contendo farelo de babaçu. Revista Brasileira de Zootecnia, Viçosa, MG, v. 37, n. 11, p. 2063-2068, 2008. Disponível em: <http://www.scielo.br/ scielo. php? pid=S1516-35982008001100024\&script=sci_artte $x t>$. Acesso em: 6 mar. 2012, às 13h41min.

XENOFONTE, A. R. B. et al. Características de carcaça de ovinos em crescimento alimentados com rações contendo farelo de babaçu. Revista Brasileira de Zootecnia, Viçosa, MG, v. 38, n. 2, p. 392-39, 2009. 